\title{
Os INTELECTUAIS E ACADÊMICOS LATINO-AMERICANOS: ENTRE DOMINADORES E DOMINADOS
}

\section{INTELLECTUAL AND LATIN AMERICAN ACADEMICS: BETWEEN DOMINATORS AND DOMINATES}

\author{
Raoni Machado Jardim \\ Doutor em Sociologia pelo Centro de Estudos Latino-americanos (ELA/UNB). \\ Professor da Faculdade de Educação da Universidade de Brasília (FE/UnB). \\ ORCID: https://orcid.org/0000-0003-1398-7230 \\ raoni.mmj@gmail.com
}

\author{
Martin-Léon-Jacques Ibáńez de Novion \\ Doutor em Estudos Latino-Americanos, pela Universidade Nacional Autônoma do México \\ Professor e pesquisador do Departamento de Estudos Latino- \\ Americanos (ELA/ICS/UnB). Brasília - DF - Brasil \\ ORCID: https://orcid.org/0000-0001-7702-6696 \\ jacques.novion@gmail.com
}

Resumo: Para compreendermos o espaço em que atuam os intelectuais latino-americanos na atualidade é necessário realizar uma revisão sobre a constituição desse campo, dela extraindo, para análise crítica, a relação entre o capitalismo e o desenvolvimento das ciências e das instituiçóes acadêmicas. A naturalização do racismo epistêmico ajudou a estruturar o eurocentrismo e seus binômios hierarquizantes dentro do capitalismo moderno, sendo esta uma característica ainda marcante nos âmbitos de produção de conhecimento, seja na pesquisa ou na docência, hoje fortemente condicionados pelas diretrizes do neoliberalismo transnacional. É diante dessa explanação histórica que a posição dos intelectuais latino-americanos na estrutura acadêmica, marcada pelo paradoxo dominados-dominadores, deve ser analisada. O engajamento deles na abertura das universidades, via uma educação intercultural, crítica, dialógica e horizontalizada será defendido como forma de superaçáo desse paradoxo rumo a um pensamento mais autônomo e representativo das realidades locais da América Latina.

Palavras-chave: Capitalismo. Educação Intercultural. Engajamento Acadêmico.

Авsтract: In order to understand the space in which Latin American intellectuals work today it is necessary to carry out a revision about the constitution of this field, drawing from it, for critical analysis, the relation between capitalism, the development of sciences and academic institution. The naturalization of epistemic racism has helped to structure Eurocentrism and its hierarchical binomials within modern capitalism, a feature still outstanding in the fields of knowledge production, whether in research or teaching, 
now strongly conditioned by the directives of transnational neoliberalismo. It is against this historical explanation that the position of Latin American intellectuals in the academic structure, marked by the dominated-dominating paradox, must be analyzed. Their engagement in the opening of the universities through an inter-cultural, critical, dialogical and horizontalized education will be defended as a way of overcoming this paradox towards a more autonomous and representative thinking of the local realities of Latin America.

Keywords: Capitalism. Intercultural Education. Academic Engagement.

\section{A Racionalidade Moderna}

O pensamento moderno ocidental se estruturou, em grande medida, sobre a dicotomia e hierarquização étnico-racial iniciada com o processo colonial nas Américas, tendo a própria ideia de 'raça' nascido como pilar cognitivo da dominação europeia. Os genocídios e a exclusão das matrizes epistêmicas dos povos originários, e posteriormente africanos, no processo de colonização americano foi parte da estratégia que buscava a naturalização de uma cosmovisão binária sobre o mundo, na qual a Europa ocupava o seu polo positivo máximo. Inicialmente conjugada à questáo religiosa (povos 'com alma' ou 'sem alma'; povos 'com religião' ou 'sem religião') no século XVI, a questáo racial foi secularizada em termos 'científicos' no século XIX, mas ambos tinham a mesma conotação com relação à humanidade ou 'não-humanidade' dos povos indígenas e negros.

$\mathrm{Na}$ perspectiva adotada nesse trabalho, o que impulsionou a lógica binária e hierárquica entre colonizadores e colonizados, para além da crença na inferioridades das culturas indígenas e africanas, forjada por meio das categorias raciais, foi a posse das terras para a extração de matériaprima e a dominação dos povos para mão de obra, estruturando, mundialmente, o sistema-mundo capitalista (WALLERSTEIN, 2012). Significa dizer que a motivação central dessa necessidade de diferenciação não diz respeito, a priori, aos conteúdos raciais ou epistêmicos dos subalternizados. A naturalização da hierarquização étnico-racial encontrou no fator biológico-fenotípico, secularizado como desígnio divino, um mote para subalternização cultural e religiosa diante dos europeus, visando, mais do que a qualquer outro interesse, à expansão econômica e territorial. 
As relações sociais internas aos países, e também as relações entre as naçôes dentro da incipiente geopolítica mundial, foram desenvolvidas sobre a necessidade de posicionar os sujeitos e as naçóes dentro do sistema capitalista, configurando a divisão racial do trabalho em termos globais (QUIJANO, 2005). A Igreja Católica jogou um papel decisivo sobre essa naturalização, entendida, ainda que não explicitamente, como um designo divino, manifesto biologicamente e fenotipicamente: a cor da pele. Apesar de isso ter ocorrido especialmente com os povos indígenas e africanos, com uma violência sui generis, não foram apenas os povos não-europeus que sofreram marginalização epistêmica, o que se ilustra pela ainda preterida filosofia espinozista diante da cartesiana, ou a filosofia goethiana diante da newtoniana, por exemplo, que não se dobravam facilmente à lógica cognitiva do capitalismo moderno.

Essas decisóes impactaram para muito além da estrutura capitalista, moldando narrativas sociais, identidades, subjetividades, cosmovisões, enfim, criando uma hierarquia epistêmica que esteve e está intimamente vinculada com as dinâmicas de poder capitalistas. Desde uma análise das práticas culturais e educacionais no território da Nova Granada do século XVI ao XIX (CASTRO-GÓMEZ, 2005), estruturadas em torno da branquitude, até as atuais universidades atuais, fortemente submetidas a uma lógica neoliberal de produção, a relação entre a questão étnico-racial mostra o seu vínculo com o campo de produção de conhecimento, tomando como cenário mais amplo a estruturação do capitalismo moderno

Pode-se dizer que o chamado colonialismo interno (CASANOVA, 2007) é multidimensional e vem sendo perpetuado, dentro do campo acadêmico, por diretrizes acadêmicas e científicas herdadas do período colonial, sendo a esfera da produção de conhecimento um âmbito estratégico para sua naturalização. Mas antes mesmo das universidades se consolidarem nos países latino-americanos, existiu um outro momento central para a consolidação da lógica colonial nas estruturas sociais, qual seja a construçáo das narrativas que fundamentaram o sentido de pertencimento aos incipientes Estados-nação latino-americanos. Estes, constituídos por colonizadores e seus herdeiros, forjaram os termos das nacionalidades a partir da contraposição ao não-pertencimento a elas. Esta dinâmica esteve mediada, mais uma vez, pela hierarquia étnico-racial, o que significa dizer que os povos indígenas e a população negra foram excluídas dos projetos 
de nação, ainda que tenham sido explorados à exaustão como força motriz de suas estruturaçóes. Barbero (2006, p. 237), ao falar da constituição das narrativas nacionais latino-americanas, diz: "El olvido que excluye y la representación que mutila están en el orígen mismo de las narraciones que fundaran estas naciones."

Segundo Stavenhagen (2001), a configuração de um Estado independente, padrão contemporâneo predominante nascido em uma realidade europeia do século XVII e entendido como uma entidade política e legal que exerce soberania sobre um território específico e sobre seus habitantes, nem sempre coincide com uma coletividade sociológica baseada em afinidades étnicas e culturais. Assim, a maioria dos Estados atuais manteria uma ficção aparente de características monoétnicas ou uninacionais, cabendo aos pueblos e grupos étnicos a condiçáo de minorias, em contraposição à hegemonia de um grupo que busca operacionalizar, por intermédio do Estado, suas práticas e representações socioculturais. O resultado disso seria o desrespeito aos direitos fundamentais dos inúmeros conjuntos poliétnicos compreendidos nas limitadas fronteiras nacionais.

Nesse processo, a multiplicação dos binarismos que caracterizaram a modernidade auxiliou e reforçou a hierarquização racial e social, influenciando a exclusão das matrizes epistêmicas das populações latino-americanas, abrindo caminho para alçar o conhecimento gerado pela elite científica e filosófica da Europa ao status de verdade universal. O 'Eu' descartiano, ainda no século XVI, poderia produzir um conhecimento verdadeiro além do tempo e do espaço, universal, uma vez que náo estava condicionado a qualquer particularidade e 'objetivo', sendo entendido da mesma forma que a 'neutralidade' divina. Dado o seu lugar de fala e a geografia do poder na época, seu postulado de conhecimento se traduziu em um eurocentrismo universalizante e atemporal. O filósofo francês defendeu que quanto maior a distância entre o sujeito conhecedor e o objeto conhecido, maior a objetividade e, logo, legitimidade do conhecimento produzido. Com isso, consolidou-se uma concepção do conhecimento que separava a sabedoria e a prática cotidiana. A oposição razão-natureza se manifestaria como a tentativa constante dos sujeitos de compreenderem as coisas ao seu redor para poder dominá-las. Segundo Dussel (2005), o binômico sujeito conhecedor/objeto conhecido é precedido de um determinante por parte desse 'sujeito'. Não se trata de um sujeito pensante qualquer, mas sim de 
um 'sujeito-conquistador-pensante'. O ego conquiro antecede a formulação cartesiana do ego cogito. O 'Eu' pensante cartesiano e a visão dicotômica do mundo se estabeleceu atropelando o que seria o 'Eu orgânico' e a visão integrada do mundo, predominante, por exemplo, nos povos indígenas e nas culturas africanas.

Os desígnios divinos que estabeleceram o eurocentrismo foram secularizados com os binarismos cartesianos, motivando inúmeras teorizaçóes sobre o papel da razáo científico-técnica no processo de conhecimento da natureza pelos humanos com vistas ao seu controle e domesticação. Era preciso novos argumentos, mais "racionais", para legitimar a hierarquia entre os povos e posicionar os sujeitos dentro dos sistemas produtivos. Assim, estabeleceu-se a relação intrínseca entre a divisão de trabalho intelectual e a divisão racial do trabalho, bem como entre o capitalismo moderno e o desenvolvimento da ciência ocidental. No final do século XVIII, quando as universidades deixaram de ser cristâs e se transformaram em humboldtianas (MAGALHÁES, 2006), apoiadas na filosofia kantiana, qualquer forma de conhecimento que não fosse de origem daqueles países estaria proibida ou subalternizada e, portanto, fora das instituiçôes de ensino (BURKE, 2015). Além da hierarquia entre os chamados conhecimentos ocidentais hegemônicos e os subalternizados, o que pode ser verificado com a predominância do pensamento descartiano sobre o espinozista, ou da física newtoniana em detrimento da goethiana. (JARDIM, 2019)

Internamente à academia, o século XIX também foi marcado pelo processo de disciplinarização, entendido como a institucionalização em profissôes de um conjunto de práticas intelectuais distintas. Segundo Carvalho e Flórez-Flórez (2014, p. 132), cada disciplina foi criando o seu território, suas fronteiras, tradições e campos, solicitando "credenciais" aos possíveis interessados em ingressar no seu território, que tomou forma física nos edifícios, departamentos e salas, sendo a interdisciplinaridade e a transdisciplinaridade ainda hoje marginais na academia.

Pode-se dizer, ainda de acordo com esses autores, que as heranças coloniais eurocêntricas conformaram as instituiçóes acadêmicas na América Latina e no Caribe, fazendo-as réplicas quase perfeitas das instituiçôes educativas modernas europeias do início do século XIX, que por sua vez seguiam as reformas napoleônicas, na França, e humboldtianas, na Alemanha. Se as universidades em territórios de domínio espanhol nessa 
região, ao final do século XVI, seguiam o modelo das instituiçôes católicas espanholas, no Brasil, o governo português se limitou a criar instituiçóes de ensino superior apenas durante a segunda metade do século XIX, sendo estes projetos eurocêntricos e ocidentais já no estilo da Revoluçáo Industrial. As universidades transladaram esse projeto para o Brasil durante a década de 1930. Nesse projeto, nada anterior a chegada dos europeus nas Américas estava presente.

\section{Contextualização Crítica sobre as Consequências da Racionalidade Ocidental Moderna na América Latina}

Nos últimos anos, apesar de termos presenciado no Brasil uma maior inclusão de negros e indígenas na educação formal, especialmente no ensino superior a partir da criação de políticas de cotas para negros e indígenas (IBGE, 2016), em diversos países da região, os currículos e metodologias seguem centrados, majoritariamente, nas tradiçóes europeias ou estadunidenses. A exclusividade da cultura científica, letrada e baseada no idioma colonial ignorou, e segue ignorando, as outras formas possíveis de construção e transmissão de conhecimentos. Mesmo dentro daquela matriz ocidental moderna colonial, os sujeitos subalternizados, pela discriminação racial e pela insuficiência de recursos financeiros, seguem tendo imensa dificuldade em se capacitarem dentro do ensino formal para ocupar uma posiçáo dentro do projeto de modernidade que os habilite a levar a público as suas narrativas sobre a história e sobre o mundo atual.

Dentro da concepção adotada nesse trabalho, essas duas dimensôes de análise - a exclusão epistêmica e a dificuldade de acesso ao ensino formal - estáo intrinsecamente relacionadas na atualidade, tal como demostra o IBGE (2010), assim como as questóes étnico-raciais e socioeconômicas, como dito acima (JARDIM, 2019). Esse ciclo se retroalimenta pela dificuldade imposta aos sujeitos subalternizados ${ }^{1}$ de acesso à educação formal, inviabilizando uma realidade educacional pluriepistêmica e mais democrática.

A política de cotas étnicas e raciais adotadas no Brasil a partir de 2002 e sancionada como lei em 2012 (Lei n ${ }^{\circ}$ 12.711/2012) alterou 
substancialmente esse quadro. Essa política de ação afirmativa tem como propósito reverter o racismo histórico como padrão social de desigualdade, injustiça, crueldade e discriminação (CARVALHO, 2004; CARVALHO; FLÓREZ-FLÓREZ; MARTÍNEZ, 2017). Ainda que as universidades tenham um perfil majoritariamente branco, o percentual de negros vem aumentando substancialmente, quase dobrando entre 2005 e 2015, o que se relaciona diretamente com as cotas. (IBGE, 2016; INEP, 2013; JARDIM, 2017)

A participação marcante da militância negra nos anos 1980, durante a Constituinte, e nos anos 1990, durante a elaboraçáo da Lei de Diretrizes e Bases da Educação (Lei 9.394/96), não foram suficientes para incluir de fato as reivindicaçóes desses movimentos sobre inclusão epistêmica de matriz africana na educação formal. Foram sim inseridas, de maneira parcial, genérica e distorcidas, tal como consta no Art.26 da LDB, em seu inciso $4^{\circ}$ e em sua revisão com a Lei 10.639/2003, que inclui nesse artigo a obrigatoriedade do ensino de História da África e das culturas afro-brasileiras nas escolas públicas e particulares dos ensinos fundamental e médio. Esse último momento se deu em meio ao debate sobre cotas raciais e a um momento político favorável ao debate racial dentro das políticas públicas. Esse artigo foi novamente modificado pela Lei 11.645/2008, que manteve, em outras palavras, a determinaçáo já colocada e as suas formas de aplicação. O artigo foi mantido mesmo após o golpe parlamentar de 2016 e a lamentável reforma por qual passou a LDB em 2017, que, dentre outras modificaçóes, estipulou a não obrigatoriedade do ensino da Filosofia e da Sociologia enquanto disciplinas obrigatórias para o ensino médio.

Apesar de avanços pontuais, uma breve análise dos currículos escolares, e até mesmo das ementas das disciplinas da pós-graduação, dentro das mais diversas áreas, demonstram com facilidade a perpetuação desse quadro de soberania das narrativas, teorias e metodologias de ensino europeias, herdada do colonialismo e, mais atualmente, das estadunidenses, resultante da forte penetração do neoliberalismo nesse campo acadêmico, escolar e da pesquisa. E não são apenas as leis que são descumpridas. A chamada Convenção 169, cujo Brasil é signatário por meio do Decreto Legislativo N5051/2004, assegura, em sua Parte VI, Artigos 26 a 31, uma séries de determinaçóes, ignoradas pelas autoridades brasileiras, com relação à educação indígena. A Constituição Federal, em seu capítulo III, 
Seção I, Artigo 2010, inciso 2 tampouco é cumprida. Mais do que marcos legais, necessitamos de fiscalizaçáo quanto ao cumprimento desses marcos.

\section{Os Debates em Torno do Engajamento Intelectual Latino-Americano}

A alteraçáo da realidade educacional e acadêmica brasileira, e em grande parte da América Latina, se situa em um campo amplo. Os currículos monoepistêmicos e eurocentrados de grande parte das instituiçóes de ensino não representam a diversidade cultural dos países dessa região e refletem um projeto de poder hegemônico e vigente desde a colonização. Logo, a alteração dos currículos disciplinares passa, também, por uma luta sobre as narrativas nacionais, sobre as disputas de projetos de poder. É importante lembrar que nem todo projeto de poder se pretende totalitário. Há os que se pautam pelo respeito e participação efetiva de todos os sujeitos e segmentos culturais nas instâncias de tomada de decisão e de elaboração de narrativas. Esses projetos já encontraram avanços importantes, não sem contradiçôes, em países como o Equador e a Bolívia, que contaram com a participação efetiva do movimento indígena na formulação das constituiçôes nacionais e no estabelecimento de Estados Plurinacionais. (WALSH, 2012)

Essa reflexão aproxima as análises sobre os colonialismos e imperialismos dentro dos paradigmas científicos latino-americanos, buscando perceber em que medida ocorrem reproduçóes, ainda que não intencionais, de colonialidades na atualidade. A Sociologia do Conhecimento nessa região não deve se furtar a este debate. Toda proposta de vigilância epistêmica que esse campo propóe, e sobre o qual se estrutura, clama pela contextualizaçáo do conhecimento e instiga os intelectuais a perceberem e se engajarem na luta de poder que existe no campo científico e acadêmico, sendo esta parte da luta de classes e contra as opressóes étnico-raciais.

Certamente que os intelectuais compóem uma força importante na luta pela defesa e valorização dos conhecimentos tradicionais. Mais do que isso, eles são atores decisivos para o alargamento das fronteiras institucionais acadêmicas e científicas no sentido de propiciar a criação de espaços que garantam a presença dos sujeitos das comunidades tradicionais, reco- 
nhecendo que não há quem possa falar por eles melhor do que eles próprios. A alteração da realidade do ensino formal, nos seus diversos níveis, atravessa a organizaçáo da sociedade civil, especialmente dos segmentos subalternizados e excluídos física e epistemicamente das instituiçôes e dos currículos de ensino. Passa, também, pela atuação do seu quadro docente, de pesquisadores e dos intelectuais de forma geral, partindo, antes de mais nada, do exercício constante de vigilância epistêmica.

O engajamento intelectual sobre as questôes de apelo social vem de uma tradição teórica consideravelmente longa, remetendo, inicialmente, ao caso Dreyfus (ALTAMIRANO, 2002). Aliás, substâncias dessa discussão podem ser mapeadas anteriormente ao caso Dreyfus, estando presente, porém sem a mesma clareza, na obra de Marx e em sua crença de que o pensamento está intimamente vinculado com as condiçôes socioeconômicas, sendo papel dos intelectuais o engajamento na tentativa de instrumentalizar a consciência de classe e a sua posterior expansão para a ação revolucionária.

Uma obra de Marx, particularmente, parece revelar essa noção de engajamento intelectual, qual seja as suas Teses sobre Feuerbach, datadas possivelmente de 1845. A crítica que Marx (1845) faz a seu colega, mais do que desmistificar o materialismo e o idealismo hegeliano, é advogar sobre o sentido da práxis, enquanto uma atividade revolucionária que concilia teoria e prática. A teoria seria modificada pela experiência prática, que por sua vez se modifica constantemente pela teoria. Sua maior preocupação, como demonstrado na última das onze teses, é com a imparcialidade interpretativa dos filósofos diante da realidade social: "Os filósofos não fizeram mais que interpretar o mundo de forma diferente; trata-se porém de modificá-lo.” (MARX, 1999 [1845], p. 8)

\section{Análise Crítica sobre o Atual Sistema de Produção de Conhecimento}

Grande parte da problematização sobre a chamada colonialidade do saber é feita a partir das análises críticas dos eurocentrismos nas narrativas oficiais, sobre as produçóes de conhecimento diversas a respeito da América Latina e suas influências na atualidade. No entanto, não são muitos os tra- 
balhos que se aprofundam na reflexão sobre o atual quadro de indução da produção de conhecimento nessa região. Além de uma revisão crítica do eurocentrismo, seria preciso levar a problematizaçáo sobre a colonialidade do saber, de forma sistemática, para a matriz hegemônica estadunidense, inclusive apontando o modo como essa mesma colonialidade pôde ser cooptada pelo neoliberalismo (RIVERA, 2010; BROWITT, 2014). Se no primeiro momento as demandas capitalistas por quadros especializados estabeleceram uma visão fragmentada da realidade, refletindo em uma correspondente institucionalização universitária em faculdades, departamentos, disciplinas e programas, com pouca ou nenhuma mobilidade possível entre alunos e professores, esse mesmo capitalismo, em sua versão neoliberal, manteve a rigidez epistêmica na atualidade, hierarquizando os campos de saber pela seletiva distribuição de recursos.

Novion (2014) discorre sobre as políticas hegemônicas estadunidenses, iniciadas com a independência desse país, e que se estendem até a atualidade, centradas no binômio integração-segurança, sendo a comunidade latino-americana e caribenha alvo constante da atuação hegemônica dessa nação, motivada especialmente pela intenção de reposicionar essas comunidades dentro da divisão internacional do trabalho e de definir o acesso aos recursos, riquezas e conhecimentos, mantendo a produção e reprodução do Sistema-Mundo capitalista (WALLERSTEIN, 2012). Mais do que descrever cada um desses momentos, nos interessa chamar atenção para como o despontamento e a manutenção dos Estados Unidos como grande potencia mundial está vinculada com a sujeição da América Latina às suas políticas econômicas, e como estas vão sendo escamoteadas por distintas narrativas ideológicas para legitimá-las. O êxito dessas políticas de integração foi facilitado pelo progressivo aprofundamento das relaçóes entre as elites políticas e militares estadunidenses e as dos países latino-americanos, fato ainda recente na memória de muitos de nós e que se renova com a atual onda de fascismo e de militarização da política em diversos países da região. Para Novion (2014), o binômio tem mais relação com a segurança que com a integração. São as diferentes doutrinas estabelecidas em diferentes épocas no continente que têm possibilitado a implantação da lógica hegemônica de integraçáo.

O Consenso de Washington, a partir dos anos 1980, materializa esse tipo de prática hegemônica naturalizando o neoliberalismo como uma 
realidade incontornável, por meio dos acordos com as elites do continente. Os reflexos desse processo na academia foram evidentes. Borón (2005) esclarece como as universidades latino-americanas, sob o signo das políticas neoliberais, sofreram novo regime de produção, definido pelo autor como contrarreforma universitária, que consistiu em limitar a autonomia dos recursos financeiros de que disponham as universidades levando-as a recorrer a fontes externas como BM, FMI e BID. Na condição de grandes expoentes do sistema neoliberal, esses atores impunham como condiçáo para os empréstimos realizados projetos específicos de investigação que deveriam responder a problemas, teorias, hipóteses, metodologia e linguagens. Esta contrarreforma foi, na prática, operacionalizada pela redução da remuneração básica dos professores a um piso mínimo, outorgando seletivamente complementos salariais em função dos critérios de produtividade acadêmica (também chamadas de 'estímulos à produção'). Essa seria medida pela quantidade de publicaçóes em revistas de grande circulação e pelo número de citação de autores de grande referência, ou seja, aqueles bastante citados que publicam nas revistas de grande circulação, encerrando um ciclo restrito e autorreferente de atribuição de prestígio e remuneração. Esses são os indicadores, geralmente originados nas chamadas ciências 'duras' (Matemática, Física, Química etc.) nas quais um trabalho é considerado importante e pelo qual os recursos são distribuídos aos autores, no caso de um novo projeto, ou à publicaçáo de uma obra, no caso de uma produção já feita.

Discorrendo sobre como ocorreu a passagem do referencial europeu para o estadunidense, resultando em temas, formas de abordagens, teorias e metodologias associadas à particularidade social da sociedade e das universidades estadunidenses e sob formas aparentemente a-históricas, Bourdieu e Wacquant (2002, p. 2) avaliam que isso se dá por meio de "teses com as quais se argumenta, mas sobre as quais não se argumenta." Não é difícil perceber a existência de uma relação dialógica entre a produção de conhecimento, especialmente nas Ciências Sociais, e as dinâmicas sociais; afinal, os atores sociais, sejam oriundos do governo ou da própria sociedade civil, buscam esse campo como referencial para compreensão da realidade e, consequentemente, para a sua modificaçáo. No momento em que o sistema capitalista torna-se mundializado, as universidades começam a se alinhar aos imperativos do mercado global, operacionalizado 
pela “(...) circulação de colóquios universitários, livros de sucesso, revistas semieruditas para relatórios de especialistas, por balanços de comissóes para capas de magazines (...)" (op.cit., p.15-16)

Esse circuito, articulado pelas chamadas redes de atores transnacionais de caráter neoliberal, logra atribuir legitimidade científica aos estudos e pesquisas, criando termos e reconceituando outros que, estrategicamente, carregam consigo significados fundamentais para a compreensão das dinâmicas sociais. É por meio dessas redes que se levaria a cabo o fluxo do Sul para o Norte. Para dar movimento ao fluxo, são oferecidos títulos, boas condiçôes de salário e instalação, bolsas para indígenas e afrodescendentes, oportunidades de publicação, entre outros, o que dificilmente seria alcançado em universidades públicas da América Latina, especialmente em momentos de crise. Por fim, esse fluxo, condicionado pela política de citaçôes de seus pares, termina por impregnar as produçóes com ideias externas que apenas em parte incluem a análise da real dinâmica dos países da região (RIVERA, 2010). Enquanto complemento do fluxo do Sul para o Norte, existe ainda o contrafluxo do Norte para o Sul. Referimo-nos às manipulaçóes de termos fundamentais para o pensamento social que ocorrem a partir dos centros hegemônicos na direção do restante do mundo, configurando cognitivamente uma lógica teórica inócua à identificação de atores e às estratégias de manutenção do status quo. Trata-se, portanto, de desvios semióticos que ocultam a realidade, ao mesmo tempo em que criam narrativas coerentes que facilitam a naturalização do neoliberalismo enquanto uma realidade dada.

Um termo, em particular, revela-se especialmente problemático e relevante quanto à superação do seu sentido original para Ciências Sociais de países latino-americanos, caracterizados por desigualdades e concentraçôes de renda crônicas, qual seja o termo 'classe', como demostram Stratta e Barrera (2009). Argumenta Jardim (2010) que essa manipulação trouxe efeitos danosos para a luta de atores sociais, como no caso dos chamados novos movimentos sociais latino-americanos. Ainda sobre esse tema, apontamos os riscos na tentativa de forjar uma dicotomia entre as classes sociais e as 'identidades', ou entre os "velhos movimentos sociais" e os "novos movimentos sociais." (GONH, 1997) Grüner (2008, p.34) questiona que, ainda que seja evidente que existam identidades, a exemplo da racial ou da sexual, que em sua origem são completamente independen- 
tes dos processos econômicos ou sócio-políticos, "quién podría seriamente sostener que el desarrollo de la lucha de clases no tiene influencia sobre la situación de los negros o de las mujeres?"

Com relação à identificação de atores de caráter neoliberal que buscam atuar e induzir a esfera da produção de conhecimento, o BM pode ser destacado como um importante agente no processo de consolidação do imperialismo cultural norte-americano, tendo destaque especial no desenvolvimento de diretrizes educacionais para a diversidade cultural em países latino-americanos. Apesar da diferença de posiçóes entre os experts dessa instituição, os elementos inspiradores de suas recomendaçóes em matéria de política educativa relacionada à diversidade cultural e a políticas de equidade giram em torno da rentabilidade da educação, da aplicação da relação custo/benefício e da intervenção por meio de programas focalizados e compensatórios, o que pode ser verificado com a análise de documentos como Prioridades e Estratégias para la Educación e La Educación en América Latina y el Caribe (DOMENECH, 2007). A parceria do BM com FMI, OMC e Departamento de Tesouro dos Estados Unidos e suas alianças estratégicas com organismos como as Naçóes Unidas e outras em nível regional, como o BID, resultam vitais para compreender seu avance no terreno da educação e cultura, fato comprovado por sua posição de principal fonte de financiamento externo para esses setores nos países de economias dependentes.

Mato (2007) pesquisou a presença e atuação de think tanks em países latino-americanos, evidenciando o grau de articulação e penetração da ideologia neoliberal nas universidades dessa região. Ao traçar o histórico de surgimento dos think tanks, iniciado com a fundação da Sociedade Mont Pèlerin, em 1947, fica clara a estratégia e os valores que adotavam. Preocupados com as 'ameaças' do Estado de Bem-Estar e o marxismo, eles vislumbraram a criação de institutos de estudos públicos para renovar as ideias dos intelectuais, professores e jornalistas por intermédio de investigações, conferências, seminários e publicações. Para eles, essas pessoas eram as principais geradoras de opinião pública e os políticos fariam o que a opinião pública lhe cobrasse fazer. Dessa maneira surgiram os principais centros de pensamento neoliberais, dentro os quais Mato (2007, p.33) destaca o Institute of Economics Affairs, inaugurado em 1955, em Londres, e a Atlas Economic Research Foundation, inaugurado em 1981, com sede em 
Washington, sendo que esta última dá apoio a dezesseis instituiçôes latinoamericanas. Outra rede transnacional de caráter neoliberal que deve ser ressaltada pela profusão de sua atuação na América Latina é a Fundación Internacional para la Libertad (FIL), inaugurada em 2002. Os discursos dessa instituição quanto ao seu contexto de surgimento e missão, bem como do momento político mundial a ser 'combatido' (MATO, 2007, p. 31-32), não deixam espaços para dúvidas sobre o seu conservadorismo diante dos avanços sociais na América Latina, a sua defesa do individualismo, e a centralidade do mercado para os modelos de desenvolvimento nacional.

A atuação dessa série de atores no âmbito educacional exemplifica bem a utilizaçáo do multiculturalismo enquanto elemento teórico e ideológico que vem associado ao cenário neoliberal e pós-moderno, em particular quando se busca analisar e intervir, desde países desenvolvidos, em realidades de populaçóes historicamente marginalizadas. Chauí (2006) reconstitui o trajeto do conceito de "pós-modernidade" para perceber os seus efeitos no campo da produçáo de conhecimento. Segundo a autora, Jean-François Lyotard, em 1979, examinando a mutação conceitual das ciências e a sua contraposição ao pensamento moderno desenvolvido entre os séculos XVII e XX (1970), designou a transformação que percebia como a condição pós-moderna. A sociedade não seria uma realidade orgânica nem um campo de conflitos, e sim uma rede de comunicaçôes linguísticas. As ciências, a política, a filosofia, as artes seriam jogos de linguagem, narrativas em disputa, nenhuma delas denotativa, isto é, nenhuma delas referida às coisas mesmas, à realidade. Por isso, o pós-modernismo comemora o que designa de fim da meta-narrativa, isto é, os fundamentos do conhecimento moderno, relegando à condição de mitos eurocêntricos totalitários os conceitos que fundaram e orientaram a modernidade. Segundo a autora, a política pós-moderna opera grandes inversôes: substitui a lógica da produção pela da circulação, acarretando na substituição da lógica do trabalho pela da informação; substitui, também, a luta de classes pela satisfação-insatisfação do desejo.

Esta lógica se combina com o multiculturalismo em sua versão neoliberal, que busca novos espaços e populaçôes, potencialmente contrahegemônicos, de resistência ou com potencial para expansão de mercado. Segundo Grüner (2008, p. 76), a ideologia multiculturalista é uma forma 
de racismo negada que afirma tolerar a identidade do outro e que substitui as meta-narrativas por uma história-em-fragmentos, "renunciando casi por completo a toda preocupación por las articulaciones histórico-sociales o político-económicas de los procesos culturales." Sobre a combinação do pós-modernismo com o neoliberalismo dentro da academia, mais especificamente nas Ciências Sociais, podemos perceber, como bem aponta Borón (2005), que este último instaurou o que o autor chama de reducionismo economicista, no qual as análises privilegiam fatores causais isolados, de fundo econômico, entendidos como os principais 'fazedores da história'. Essa lente de análise histórico-social termina por estabelecer também o chamado 'individualismo metodológico' que, entre outras coisas, consagra o desaparecimento dos atores coletivos. Sob essas duas perspectivas teóricas e ideológicas, a sociedade torna-se um difícil objeto de reflexão crítica, especialmente quando existe uma proposta de transformação.

\section{Intelectuais Latino-Americanos: Entre Dominadores e Dominados}

A exposição feita anteriormente busca problematizar o cenário em que se localizam e movem os intelectuais latino-americanos no sistema de produção do conhecimento na atualidade. De forma geral, pode-se dizer que o paradigma em torno do termo 'intelectual' transita entre as posiçóes de dominadores e dominados, seja na esfera nacional ou global. Dentro de uma estrutura social mais ampla que inclui os interesses dos atores globais, os intelectuais, para garantirem sua progressão na carreira e suas publicaçôes, se adequam às diretrizes estipuladas pelo regime de mercado existente. Eles, portanto, ocupariam a posição de dominados. Considerando os contextos nacionais, nos quais a perpetuação das diretrizes acadêmicas de produção do conhecimento são hegemônicas, os intelectuais, enquanto categoria profissional responsáveis pela produção de conhecimento que serve de base para a formação de muitos sujeitos, estariam na posição de dominadores.

A autonomia racional das artes, ciências, técnicas, filosofia, ética e direito foi fortemente influenciada pela forma tomada pela divisão social de classes dentro do sistema capitalista, com a separação entre o trabalho 
manual e o trabalho intelectual. Porém, as elites acadêmicas e intelectuais mundiais, guiadas pelos projetos de poder de suas nações e empresas, buscaram o ocultamento da determinação material da racionalidade, tal como se o espírito (ideias) pudesse determinar a materialidade socioeconômica (as condiçóes de classe) e fosse ele capaz de produzir o real e a marcha da história. Como dito, a dimensão analítica de classe foi e ainda é ocultada por diversos mecanismos desenvolvidos por atores neoliberais que atuam no âmbito acadêmico latino-americano, marcadamente em campos disciplinares e instituiçóes que mantêm relaçôes com movimentos sociais, tal como os Estudos Culturais (JAMESON, 2008). Essa é uma estratégia para a inclusão de possíveis atores contestatários ao status quo capitalista neoliberal, com fim de neutralizá-lo e, ainda, criar um novo público para consumo dos seus produtos e ideologia. Nesse sentido, tornam-se estratégicos essa rede neoliberal os campos acadêmicos ligados ao estudo de "minorias" e/ou vinculados a movimentos sociais.

Dentro do processo nomeado 'modernização' que experimentamos há mais de cinco séculos, os intelectuais já não têm renda financeira livre, como era comum na elite clássica: dependem de um salário corrente, muitas vezes obtido no campo universitário ou em instituiçôes burocráticas e educacionais, na administração de bens culturais e, muito ocasionalmente, em pesquisas científicas, ambos submetidos aos estímulos à produção de que falamos, ainda que mediados pelos Estados nacionais. Assim, ao se adequar a essa realidade, o intelectual perpetua a sua vigência. Ao mesmo tempo, a sua imagem segue sendo renovada como a de um líder formador; de um sujeito que leva a razão aonde não havia.

$\mathrm{Na}$ América Latina são comuns os usos de 'intelectual', 'pesquisador', 'estudioso' - termos às vezes usados como sinônimos - associados à ideia de produçáo exclusivamente ligada à academia. Esses termos, limitados em sua uni-significação, são reafirmados por discursos que fazem parte da agenda modernizadora ditada pelos governos, mídia universitária e diretrizes editoriais, em meio aos quais se tenta fornecer normas, delimitar e controlar as produçóes intelectuais em termos de sua produtividade. Essa dinâmica, fechada em si mesma, leva à desvalorização de práticas, estudos e produçóes extra-acadêmicas. Como consequência, as instituiçôes acadêmicas se distanciam da sociedade e dos problemas cotidianos aos quais deveriam servir. 
Pode-se dizer que, no que diz respeito principalmente à esfera política e econômica, além das clássicas teorias sociais, os intelectuais latinoamericanos se baseiam majoritariamente em estudos e obras de origem estadunidense e europeia. Essa é uma dinâmica unilateral, na maioria dos casos, uma vez que as contribuiçóes teóricas latino-americanas são pouco consideradas por estudiosos norte-americanos e europeus - em geral ocupam um lugar de fonte de informaçóes de testemunhos ou pontos de vista locais, principalmente pela falta de fluência nas línguas portuguesa e castelhana. Inclusive, em uma esfera latino-americana, nossa mentalidade colonizada faz com que, às vezes, seja necessário primeiro reconhecer autores latino-americanos no âmbito internacional, para, depois, serem considerados na esfera continental. (MATO, 2007)

\section{Apontamentos sobre uma Práxis Intelectual Latino-Americana}

Considerando a ideia desenvolvida por Gramsci (1960) - de que o índice de hegemonia de uma classe pode ser medido pela sua capacidade de gerar intelectuais orgânicos criticamente engajados, permitindo um aumento da condição econômico-corporativa da sua classe -, parece evidente a importância da democratização e expansão da educação, bem como da aproximação entre os acadêmicos e intelectuais e as diferentes realidades sociais em que se encontram inseridos. Esse processo deve partir de uma profunda reflexão pessoal, dirigida ao campo acadêmico como um todo, sobre a reproduçáo das colonialidades do saber na atualidade e seus efeitos sobre a manutençáo de um quadro de opressão e marginalização de amplas parcelas da populaçáo, especialmente os sujeitos historicamente subalternizados. Como diz Carvalho e Águas (2016, p. 1024): "Descolonizar-se, para um acadêmico latino-americano, significa, entre outras coisas, admitir que não fomos capazes de incorporar plenamente os saberes dos mestres afro e indígenas, simplesmente porque atribuímos a posição de maestria apenas aos sábios dos países centrais do Ocidente.'

Encaminhando ao fim deste trabalho, gostaríamos de concluir dizendo que a ruptura com o paradigma hegemônico da produção de conhe- 
cimento baseada em contextos externos é uma tarefa complexa e pode ser trabalhada a partir de diferentes campos de ação. Internamente à academia e às estruturas escolares, uma reforma curricular que reflita mais fidedignamente os processos históricos e que incluam narrativas subalternalizadas seria fundamental, bem como a expansão da inter e transdisciplinaridade; o fortalecimento e valorização das atividades de extensão; o contato entre acadêmicos, estudantes e outros segmentos sociais; as açôes afirmativas e a abertura de espaço teórico, metodológico e epistêmico para o protagonismo de sujeitos historicamente marginalizados; a produção de conhecimento colaborativa; entre outras. Também seria necessário avançar na análise relacional entre os contextos micro (academia) e macro (relaçóes entre países), valorizando as perspectivas políticas e econômicas que consideram a diversidade intelectual como parte da riqueza cultural latino-americana. Compóem-se com aqueles que pensam ser este um importante passo para outras sínteses e outras contribuiçóes, que tenham mais relação com nossas realidades e sua relaçáo com o mundo.

Essa reflexão está relacionada com o resgate do conceito de engajamento intelectual enquanto uma figura que intervém criticamente na realidade em que vive, preocupado em problematizar e desenvolver conteúdos dentro de uma racionalidade própria, expressa nas diversas formas de produzir conhecimento. Chauí (2006) diferencia o intelectual e o ideólogo: enquanto o primeiro toma posição no interior da luta de classes contra a forma de exploração e dominação vigentes, o segundo fala a favor da ordem vigente, justificando-a e legitimando-a. Tendo a noção marxista de práxis em mente, é importante destacar a necessidade de refletir sobre o conhecimento produzido e consumido na América Latina que, em última instância, serve como base para pensar seus problemas internos. É preciso que se popularize o questionamento crítico sobre os atores envolvidos; as estratégias em vigência; as imposiçôes de termos, de paradigmas teóricos, metodológicos e linguísticos, em sua maioria importados e baseados em outros países, particularmente os Estados Unidos. Trata-se de unificar, portanto, o trabalho teórico, político e prático, tal como afirmou Paulo Freire (1974). Fora de uma prática transformadora, qualquer teorização crítica à forma como se produz conhecimento e às induçôes coloniais ainda presentes, mesmo em sua nova ideologia neoliberal, corre o risco de tornar-se insumo para esse mesmo sistema. 


\section{Nota}

1 Sobre o analfabetismo entre as populaçôes branca e negra, ver PNAD, 2013. Sobre o analfabetismo entre indígenas, ver Censo Escolar de 2010 (EDUCACENSO/INEP). Sobre as taxas de frequência líquida no ensino superior entre os segmentos raciais, ver INEP (2013). Sobre a relação entre raça, renda e escolaridade, ver a Pesquisa Mensal de Emprego (IBGE, 2014).

\section{Referências}

ALTAMIRANO, C. Términos críticos de Sociología de la Cultura. Buenos Aires: Paidós, 2002.

BARBERO, J. M. Los bicentenarios latinoamericanos: nación y democracia. Nuestros malestares en lo nacional. En: NUN, José; GRIMSON, Alejandro. Convivencia y buen gobierno: Nación y democracia en América Latina. Bueno Aires: Edhasa, 2006.

BORÓN, A. Las ciencias sociales en la era neoliberal: entre la academia y el pensamiento crítico. XXV Congresso ALAS, 25, ago. 2005, Porto Alegre, Brasil. Anais. Porto Alegre, 2005.

BOURDIEU, P.; WACQUANT, L. Sobre as Artimanhas da Razão Imperialista. Revista Estudos Afro-Asiáticos. Rio de Janeiro, v. 24, n. 1, p. 15-33, 2002.

BRASIL, Lei no 12.711/12. Dispóe sobre o ingresso nas universidades federais e nas instituições federais de ensino técnico de nível médio e dá outras providências 2012. Disponível em http://www.planalto.gov.br/ccivil_03/_ato2011-2014/2012/lei/l12711.htm.

BRASIL. Lei no 9.394, de 20 de dezembro de 1996. Estabelece as diretrizes e bases da educação nacional. Diário Oficial da União. Brasília, 23 dez. 1996.

BRASIL. Lei no 10.639, de 9 de janeiro de 2008. Altera a Lei no 9.394, de 20 de dezembro de 1996, que estabelece as diretrizes e bases da educação nacional, para incluir no currículo oficial da Rede de Ensino a obrigatoriedade da temática "História e Cultura Afro-Brasileira”, e dá outras providências. Diário Oficial da União. Brasília, 10 jan. 2003.

BRASIL. Lei no 11.645, de 10 de março de 2008. Altera a Lei no 9.394, de 20 de dezembro de 1996, modificada pela Lei no 10.639, de 9 de janeiro de 2003, que estabelece as diretrizes e bases da educação nacional, para incluir no currículo oficial da rede de ensino a obrigatoriedade da temática "História e Cultura Afro-Brasileira e Indígena”. Diário Oficial da União. Brasília, 11 mar. 2008. 
BRASIL. Decreto no 5.051, de 19 de abril de 2004. Promulga a Convenção no 169 da Organização Internacional do Trabalho - OIT sobre Povos Indígenas e Tribais. Disponível em http:/www.planalto.gov.br/ccivil_03/_ato2004-2006/2004/decreto/ d5051.htm

BRASIL. CONSTITUIÇÃO DA REPÚBLICA FEDERATIVA DO BRASIL DE 1988. Disponível em http://www.planalto.gov.br/ccivil_03/constituicao/constituicao.htm

BROWITT, J. La teoria decolonial: buscando la identidade em el mercado académico. Cuaderno de Literatura, v. 18, n. 36, jul./dez. 2014.

BURKE, P. O que é história do conhecimento? Tradução Cláudia Freire. São Paulo: Ed. Unesp, 2015.

CARVALHO, J. J. A inclusão étnica e racial do ensino superior: um desafio para as universidades brasileiras. En: SEMANA DA CONSCIENCIA NEGRA, 2., 2004, Novo Hamburgo. Anais. Novo Hamburgo, 2004.

CARVALHO, J. J.; ÁGUAS, C. Encontro de Saberes: Um desafio Teórico, Político e Epistemológico. En: SANTOS, B. S.; CUNHA, Teresa (Org.). Actas do Colóquio Internacional Epistemologias do Sul: Aprendizagens globais Sul-Sul, Sul-Norte e NorteSul. Democratizar a democracia. Coimbra: Universidade de Coimbra: 2015, v. 1.

CARVALHO, J. J.; FLÓREZ-FLÓREZ, J. Encuentro de Saberes: Proyecto para decolonizar el conocimiento universitário eurocéntrico. Revista Nómadas (Col), Universidad Central. Bogotá, Colombia, n. 41, p.131-147, oct. 2014.

CARVALHO, J. J.; FLÓREZ-FLÓREZ, J.; MARTÍNEZ, M. El Encuentro de Saberes: Hacia una universidad pluriepistemica. En: AYALA, N. A. C.; RESTREPO, C. A. Saberes nómadas: Derivas del pensamiento propio. Bogotá, Colômbia: Universidad Central. Instituto de Estudios Sociales Contemporáneos - IESCO, 2017. CASTRO-GÓMEZ, S. La Hybris del punto cero:ciencia, raza e ilustración en la Nueva Granada (1750-1816). Revista Nómadas, n. 26, 2007, p. 247-250, Universidad Central. Bogotá, Colombia, 2005.

CASANOVA, P. G. Colonialismo interno. A teoria marxista hoje. Problemas e perspectivas. En: BORON, A. A.; AMADEO, J.; GONZALEZ, S. A teoria marxista hoje: Problemas e perspectivas. Buenos Aires: CLACSO, 2007.

CHAUÍ, M. Intelectual engajado: uma figura em extinção? En: NOVAES, A. (Org.). O silêncio dos intelectuais. Sáo Paulo: Companhia das Letras, 2006.

DOMENECH, E. El Banco Mundial en el País de la Desigualdad: Políticas y discursos neoliberales sobre diversidad cultural y educación en América Latina. En: ALEJANDRO, G. (Coord.). Cultura y neoliberalismo. Buenos Aires: CLACSO, 2007. p. 61-89. 
DUSSEL, E. Europa, modernidade e eurocentrismo. En: LANDER, E. (Org.). $A$ colonialidade do saber: eurocentrismo e ciências sociais. Perspectivas latino-americanas. Ciudad Autónoma de Buenos Aires, Argentina: CLACSO, set. 2005. (Coleção Sur Sur). FREIRE, P. Pedagogia do oprimido. Rio de Janeiro: Paz e Terra, 1974.

GOHN, M. G. Teoria dos movimentos sociais: paradigmas clássicos e contemporâneos. Sáo Paulo: Loyola, 1997.

GRAMSCI, A. Los intelectuales y la organización de la cultura. Buenos Aires: Lautaro, 1960.

GRÜNER, E. Introducción: El retorno de la teoría crítica de la cultura: Una introducción alegórica a Jameson y Zizek. En: JAMESON, F.; ZIZEK, S. Estudios Culturales: Reflexiones sobre el Multiculturalismo. Buenos Aires - Barcelona - México: Paiadós, 2008. p. 11-64.

INSTITUTO BRASILEIRO DE GEOGRAFIA E ESTATÍSTICA - IBGE. Síntese de Indicadores Sociais: Uma análise das condiçôes de vida da população brasileira. 2016. Disponível em: https://biblioteca.ibge.gov.br/visualizacao/livros/liv98965.pdf. Acesso em: 20 jun. 2018.

INSTITUTO BRASILEIRO DE GEOGRAFIA E ESTATÍSTICA - IBGE. Censo Populacional. 2010. Disponível em: https://censo2010.ibge.gov.br/. Acesso em: 20 jun. 2018.

INSTITUTO NACIONAL DE ESTUDOS E PESQUISAS EDUCACIONAIS ANÍSIO TEIXEIRA (INEP). Censo do Ensino Superior. 2013. Disponível em: http:// portal.inep.gov.br/sinopses-estatisticas-da-educacao-basica. Acesso em: 20 jun. 2018.

INSTITUTO NACIONAL DE ESTUDOS E PESQUISAS EDUCACIONAIS ANÍSIO TEIXEIRA (INEP). Educacenso. 2010. Disponível em: http://censobasico. inep.gov.br/censobasico/\#/. Acesso em: 20 jun. 2018.

JAMENSON, F. Sobre los “Estudios Culturales”. Estudios Culturales: Reflexiones sobre el Multiculturalismo. En: JAMESON, F.; ZIZEK, S. Estudios Culturales: Reflexiones sobre el multiculturalismo. Buenos Aires - Barcelona - México: Paiadós, 2008. p. 69-137.

JARDIM, R. M. M. Educação intercultural e o Projeto Encontro de Saberes: Do giro decolonial ao efetivo giro epistêmico. Brasília: Novas Ediçôes Acadêmicas, 2019.

JARDIM, R. M. M. El “olvido" de la dimensión de clase en la formulación teórica de los nuevos movimientos sociales latinoamericanos. Dissertação de mestrado. Universidad Nacional San Martín - UNSAM. Disponível em: http://ri.unsam.edu.ar/greenstone/ cgi-bin/library.cgi?e=d-01000-00---off-0coltesis--00-1----0-10-0---0---0direct-10----4-----0-11--11-es-50---20-about---00-1-1-00-00--4--0--0-0-11-10-0utfZz-8-00\&a=d\&c $=$ coltesis $\& \mathrm{cl}=\mathrm{CL} 1.10 \& \mathrm{~d}=\mathrm{TMAG} \_$IDAES_2010_JRMM

MAGALHÃES, A. M. A Identidade do Ensino Superior: a Educação Superior e a Universidade. Revista Lusófona de Educação, n. 7, p. 13-40; 2006. 
MARX, K. Teses sobre Feuerbach. Fonte Digital. EbooksBrasil.org. Ed. Ridendo Castigar Mores. 1999. [1845]

MATO, D. Think Tanks, fundaciones y profesionales en la promoción de ideas (neo) liberales en América Latina. En: GRIMSON, A. Cultura y neoliberalismo. Buenos Aires: CLACSO, 2007.

NOVIÓN, M. L. J. I. Hegemonía, integración y seguridad en las américas en principios del siglo XXI. En: ENCONTRO ANUAL DA ANPOCS. 38., 2014. Disponível em: https://anpocs.com/index.php/papers-38-encontro/gt-1/gt26-1. Acesso em: 20 set. 2017.

QUIJANO, A. Colonialidade do poder, eurocentrismo e América Latina. En: LANDER, Edgardo (Org.). A colonialidade do saber: eurocentrismo e ciências sociais. Perspectivas latino-americanas. Ciudad Autonoma de Buenos Aires, Argentina: CLACSO, set. 2005. p. 227-278. (Colección Sur Sur)

RIVERA CUSICANQUI, S. Ch'ixinakax utxiwa: una reflexión sobre prácticas y discursos descolonizadores. Buenos Aires: Tinta Limón, 2010.

STAVENHAGEN, R. La questión étnica. México: El Colégio de México, Centro de Estudios Sociológicos, 2001.

STRATTA, F.; BARRERA, M. Movimientos sin clase o clase sin movimiento? Notas sobre la recepción de la teoría de los Movimientos Sociales en la Argentina. Revista Conflicto Social, año 2, n. 1, 2009.

Recebido em I ${ }^{\circ}$ mar. 2019 / Aprovado em 30 jun. 2019

\section{Para referenciar este texto:}

JARDIM, R. M.; NOVION, M. L. J. I. Os intelectuais e acadêmicos latinoamericanos: entre dominadores e dominados. EccoS - Revista Científica, São Paulo, n. 49, p. I-22, er073I, abr./jun. 2019. Disponível em: https://doi.org/I0.5585/EccoS. n49.1073I.

WALLERSTEIN, I. A análise dos sistemas-mundo como movimento do saber. En: VIEIRA, P. A.; LIMA VIEIRA, R.; FILOMENO, F. A. (Org.). O Brasil e o capitalismo histórico: passado e presente na análise dos sistemas-mundo. São Paulo: Cultura Acadêmica, 2012. p.17-28

WALSH, C. Interculturalidad y (de)colonialidad: perspectivas críticas y políticas. Visäo Global, Joaçaba, v. 15, n. 1-2, p. 61-74, 2012. 